\title{
Chemical and structural investigations on uranium oxide-based microparticles as reference materials for analytical measurements
}

\author{
Philip Kegler ${ }^{1}$ - Fabien Pointurier ${ }^{2} \cdot$ Jörg Rothe ${ }^{3} \cdot$ Kathy Dardenne $^{3} \cdot$ Tonya Vitova $^{3} \cdot$ Aaron Beck $^{3}$. \\ Simon Hammerich ${ }^{4}$. Shannon Potts ${ }^{1}$. Anne-Laure Faure ${ }^{2}$. Martina Klinkenberg ${ }^{1} \cdot$ Fabian Kreft $^{1}$. \\ Irmgard Niemeyer ${ }^{1} \cdot$ Dirk Bosbach $^{1} \cdot$ Stefan Neumeier ${ }^{1}$ (I)
}

Received: 22 December 2020 / Accepted: 3 February 2021 / Published online: 19 February 2021

(c) The Author(s) 2021

\begin{abstract}
The analysis of individual micrometre- and submicrometre-sized particles collected by IAEA's safeguards inspectors on swipe samples during in-field verification activities requires the implementation of a sustainable quality control system such as suitable microparticulate reference materials. To this end, pure and neodymium-doped uranium oxide-based microparticles utilising an aerosol-based particle production process were prepared. SEM/EDX measurements confirmed the monodispersity of the produced microspheres as well as the incorporation of $15 \mathrm{~mol} \% \mathrm{Nd}$ into the compound particles. The timeline of structural investigations mirror the ongoing alteration of particles being stored under laboratory atmosphere. While results from in-SEM Raman (CEA, DAM) on microparticles after two years storage time point to the formation of $\mathrm{U}_{3} \mathrm{O}_{8}$ and a minor fraction of schoepite phase (hydrated $\mathrm{UO}_{3}$ ), in $\mathrm{U} \mathrm{L}_{3}$-edge XAFS after four months storage time and $\mathrm{U} \mathrm{M}_{4}$-edge HR-XANES after ten months storage time spectra (INE-Beamline and ACT station @ KIT synchrotron radiation source) mainly U(IV) and $\mathrm{U}(\mathrm{V})$, respectively, was observed. These results provide new insight into ageing mechanism of the microparticles after preparation. From these results important conclusions with respect to storage conditions and shelf life of the reference particles can be drawn. The first batch of pure U-oxide microparticles produced in Juelich was successfully certified regarding the isotopic composition and the $\mathrm{U}$ amount per particle and applied in an international laboratory exercise NUSIMEP-9.
\end{abstract}

Keywords Nuclear safeguards $\cdot$ Reference materials $\cdot$ Microparticles $\cdot$ Structural investigations $\cdot$ Shelf life

Supplementary Information The online version contains supplementary material available at https://doi.org/10.1557/s4358 0-021-00024-1.

Stefan Neumeier

s.neumeier@fz-juelich.de

1 Forschungszentrum Jülich GmbH, Institute of Energy and Climate Research - Nuclear Waste Management and Reactor Safety (IEK-6), 52425 Jülich, Germany

2 CEA, DAM, DIF, 91297 Arpajon, France

3 Karlsruhe Institute of Technology, Institute for Nuclear Waste Disposal, P.O. Box 3640, 76021 Karlsruhe, Germany

4 Institute of Earth Sciences, University of Heidelberg, 69120 Heidelberg, Germany

\section{Introduction}

A significant demand on nuclear reference materials exists for the maintenance of a robust quality control (QC) system, including instrument calibration, method development and proficiency testing [1]. These materials are designed for their specific purposes intended, e.g. for age dating and safeguarding nuclear materials [1]. For instance, the Network of Analytical Laboratories (NWAL) of the International Atomic Energy Agency (IAEA) requests for well-designed micrometre- and submicrometre-sized reference particles with well-defined shape and size (monodispersity) to ensure the reliability of analytical measurements conducted on swipe samples collected during inspections in nuclear facilities. These measurements are performed by means of highly sensitive methods such as Large Geometry-Secondary Ion Mass Spectrometry (LG-SIMS), Thermal Ionisation Mass Spectrometry (TIMS) and Multi Collector Inductively Coupled Plasma Mass Spectrometry (MC-ICP-MS) to determine 
accurately the isotopic composition of particles collected on the swipe samples $[2,3]$. The results inter alia are verifying the absence of undeclared nuclear materials and activities of the inspected nuclear facility.

These nuclear particle reference materials are experimentally accessible by several preparation methods $[4,5]$. One of these preparation methods is the wet chemical approach $[5,6]$. This includes the formation of particles through the precipitation of an uranium compound from an aqueous solution by changing the $\mathrm{pH}$ and subsequent hydrothermal treatment [7]. The hydrothermal approach allows for the preparation of very well-designed particles in size and composition of high purity in milligram quantity. Very recently remarkable results are published in this regard by the groups from PNNL, Richland, US [5] and ICSM/CEA, Marcoule, France $[6,7]$.

In the safeguards laboratories of the Forschungszentrum Juelich a more physical aerosol-based approach is followed $[8,9]$. This method provides very well-designed microparticles individually distributed on a solid substrate. An optional intermediate suspension step offers a very high flexibility (i) to prepare particle mixtures from two or more batches, (ii) to increase the homogeneity of particle distribution and (iii) to control the number of particles on the planchets as well as (iv) to deposit the particles on several types of substrates, e.g. cotton swipes $[10,11]$. Thus, Blind-(QC) samples are accessible which are very close to the original swipe samples collected from the inspectors.

Here, we present our recent results on the preparation of pure and mixed U-oxide particles using the aerosol-based set-up and the structural characterisation. These investigations are the first step ahead towards Th- and Pu-doped reference materials for analytical measurements in nuclear safeguards. Additionally, the results allow for deeper understanding of shelf life and storage conditions of the reference microparticles.

\section{Materials and methods}

The procedure for the production and collection of microparticles using a Vibrating Orifice Aerosol Generator setup (VOAG, Model 3450, TSI Inc., USA) is described very briefly. Detailed information are reported by Middendorp et al. [8] and Neumeier et al. [9]. The set-up mainly consists of the aerosol generator itself, a drying column, an aerosol heater (Pressurised air heater, Dekati Ltd., Finland) and an impactor (Sturm, Austria) in which a 1 inch substrate (quartz discs, glass-like carbon discs or Si-wafers) is mounted to collect particles. For the production of pure U-oxide and mixed U/Nd-oxide particles a well-designed aqueous/ethanolic (50:50 vol.\%) nitrate solution was pumped into the aerosol generator. By means of a vibrating $\mathrm{Si}$ orifice the jet of monodisperse aerosol droplets is generated. Supported by a permanent airflow the droplets are passing the drying column and the attached aerosol heater at $T=500{ }^{\circ} \mathrm{C}$. In this part of the set-up the droplets are dried forming metal nitrate particles and decomposed yielding (mixed) oxide microparticles. Finally, the particles are collected on solid substrates that are placed in the inert impactors.

The particle size \& size distribution, morphology and chemical composition were investigated using a FEI Quanta 200 FEG scanning electron microscope (SEM, FEI, Eindhoven, Netherlands) equipped with an energy dispersive $\mathrm{X}$-ray spectroscopy (EDS) system. The measurements were performed in low vacuum mode ( $\sim 6$ mbar) using an acceleration potential between 5 and $20 \mathrm{kV}$. For the determination of the particle size distribution, a particle analysis software tool (FEI, Eindhoven, Netherlands) was employed.

The crystal structure and oxidation state of uranium was derived from results of in-SEM Raman and X-ray Absorption Spectroscopy (XAS) measurements.

The in-SEM Raman measurements were performed at CEA-DAM. Raman spectra were collected inside the SEM by means of a coupling device between the SEM (XL-30, FEI, Eindhoven, The Netherlands) and the Micro-Raman Spectrometer (MRS, In Via, Renishaw, Wotton-Under-Edge, UK). The SEM is equipped with an EDS detector and with software called GSR (acronym of Gun Shot Residue) for automated detection of microparticles whose mean atomic numbers are above a chosen threshold (typically 16). The MRS is equipped with two lasers, a $514 \mathrm{~nm}$ laser with a very small spot size $(\sim 1 \mu \mathrm{m})$ and a $785 \mathrm{~nm}$ laser with a larger spot size $(\sim 2 \mu \mathrm{m})$, but which produces lower fluorescence background. Laser powers were limited to $\sim 0.25 \mathrm{~mW}$ in order to prevent weathering effects. U-bearing particles were beforehand sparsely deposited on graphite discs (dropby-drop deposition of the ethanol solution in which the $\mathrm{U}$ particles were dispersed). Once identified and located by means of the GSR, in-SEM Raman analyses were carried out on individual particles. Combined SEM/EDX - Raman system allows obtaining a triple set of data for the same micrometric spot: morphology of the particle (electronic image), elemental composition (EDS spectrum) and chemical phases (Raman spectrum).

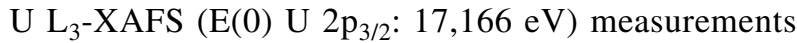
(XANES and EXAFS) have been performed at the INEBeamline for radionuclide research at the KIT light source [12]. U microparticles deposited on glass discs and covered by $13 \mu \mathrm{m}$ KAPTON® sheets have been measured in total fluorescence yield detection mode by registering $\mathrm{U}_{\alpha}$ radiation simultaneously by a 4-element and a single-element Vortex silicon drift detector. The double crystal monochromatorfitted with a pair of $\mathrm{Ge}<422>$ crystals- has been calibrated by assigning the first inflection point in the rising absorption 
edge of a standard $\mathrm{Y}$ metal foil to the corresponding $\mathrm{Y} 1 \mathrm{~s}$ binding energy ( $\mathrm{E}(0) \mathrm{Y} 1 \mathrm{~s}: 17,038 \mathrm{eV})$. The impinging radiation intensity has been recorded by an Ar filled ionisation chamber at ambient pressure. $U$ reference materials have been measured as pelletised, dispersed powders in transmission mode using 1 st and 2 nd ionisation chamber of the standard XAS set-up. The Y reference has been always measured simultaneously positioned between the 2 nd and 3rd ionisation chamber. In case of the $\mathrm{U}$ microparticles up to 31 scans have been accumulated and averaged in order to improve the signal to noise ratio of the highly dispersed materials. XANES spectra have been treated according to standard procedures (pre-edge background subtraction and edge-jump normalisation) using the Athena software [13] in order to allow for quantitative comparison.

Additionally, the U microparticles have been investigated by $\mathrm{U} \mathrm{M}_{4}$-edge HR-XANES spectroscopy carried out at the neighbouring ACT station of the CAT-ACT beamline for catalysis and actinide research [14]. Here, the incident beam has been monochromatised by a pair of $\mathrm{Si}<111>$ crystals. The energy scale has been calibrated by assigning $3725.5 \mathrm{eV}$ to the white line maximum of the $\mathrm{U} \mathrm{M}_{4}$-edge HR-XANES obtained for a $\mathrm{UO}_{2}$ reference sample. The uncertainty in the energy positions of the spectral features has been estimated to be about $\pm 0.05 \mathrm{eV}$, corresponding to half of the energy step size. The $\mathrm{U} \mathrm{M}_{4}$ HR-XANES spectra have been obtained using a Johann-type multianalyser crystal X-ray emission spectrometer. The sample, crystals, and a single diode silicon drift detector have been arranged in a vertical Rowland circle geometry. The spectra have been recorded by registering $\mathrm{U} \mathrm{M}_{\beta}$ fluorescence radiation emitted by the sample as a function of the incident photon energy. The emission energy has been selected using the (220) reflection of four spherically bent $\mathrm{Si}<110>$ analyser crystals with a bending radius of $1 \mathrm{~m}$, aligned at a Bragg angle of $75.36^{\circ}$. To improve the experimental resolution the active area of the crystals has been reduced by masks with $50 \mathrm{~mm}$ openings. The footprint of the incident beam on the sample has been defined by a $500 \times 500 \mu \mathrm{m}^{2}$ slit, additionally improving the experimental energy resolution (cf. Kauric et al. [15] for further experimental details).

\section{Results and discussion}

The particles produced by the aerosol-based process were thoroughly investigated in order to derive a deeper understanding regarding the influence of trivalent element doping on microparticle production process and properties of the microspheres. The size, size distribution, morphology and chemical composition, the crystal structure as well as the oxidation state of pure U-oxide and Nd-doped U-oxide particles investigated by means of SEM/EDS, in-SEM Raman and X-ray absorption spectroscopy, respectively. Since the aerosol-based method in Juelich is designed mainly to produce samples with individually separated microspheres the particles were collected over a duration of two hours on the same planchet in order to collect a proper number of particles on the substrate for Raman and XAS measurements.

Figure 1 depicts representative SEM micrographs of pure U-oxide (left) and Nd-doped U-oxide (right) particles. Apparently, the particles' shape and size are independent on the Nd-doping. In both batches spherical particles are produced with a mean particle size of $\sim 1.2 \mu \mathrm{m}$ in diameter and a narrow particle size distribution (inlet left).

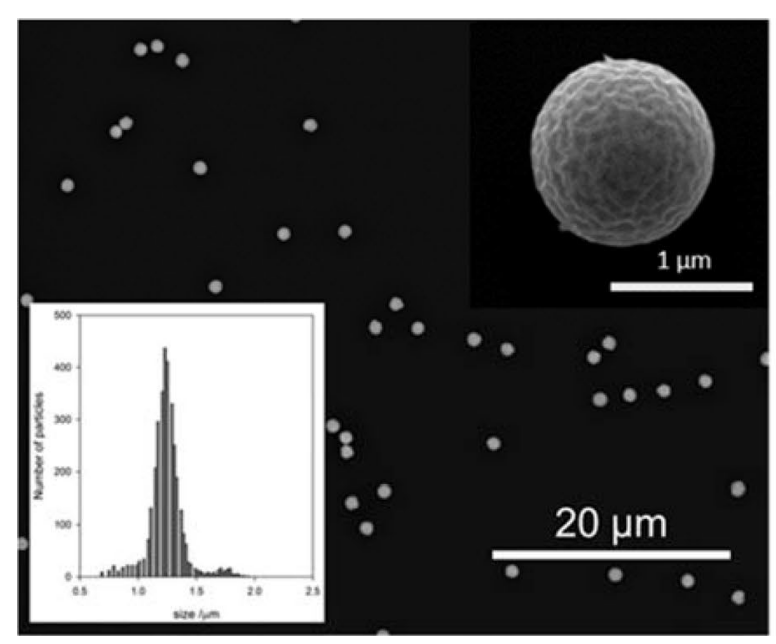

Fig. 1 Left: SEM micrographs of U-oxide microparticles distributed on a glassy carbon substrate, incl. a high-resolution SEM image of an individual particle. Inset: Particle size distribution of collected par-

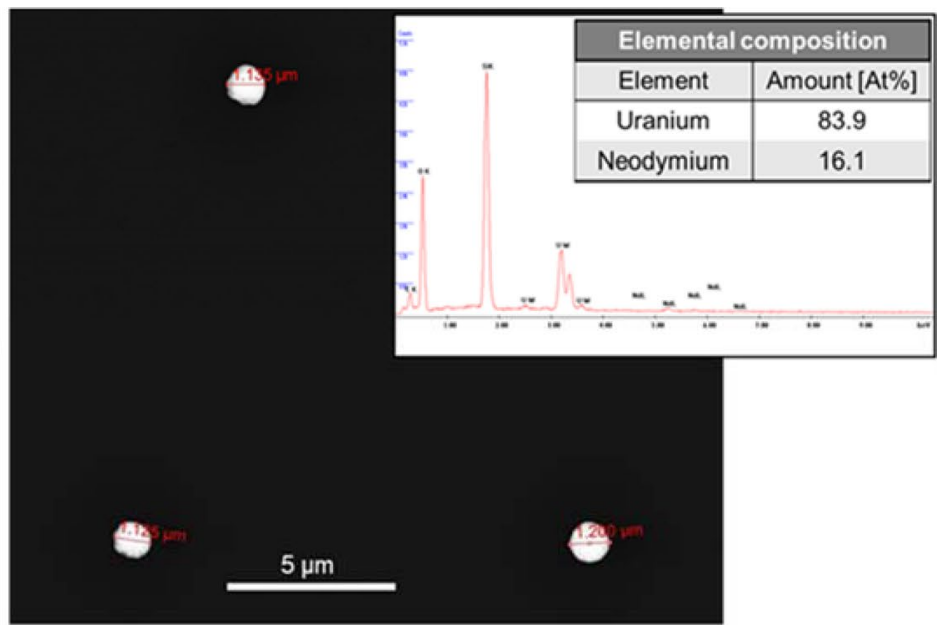

ticles. Right: SEM micrograph of individual U/Nd-oxide microparticles incl. particle size determination; Inset: EDS measurements on U/ $\mathrm{Nd}$ microparticles 

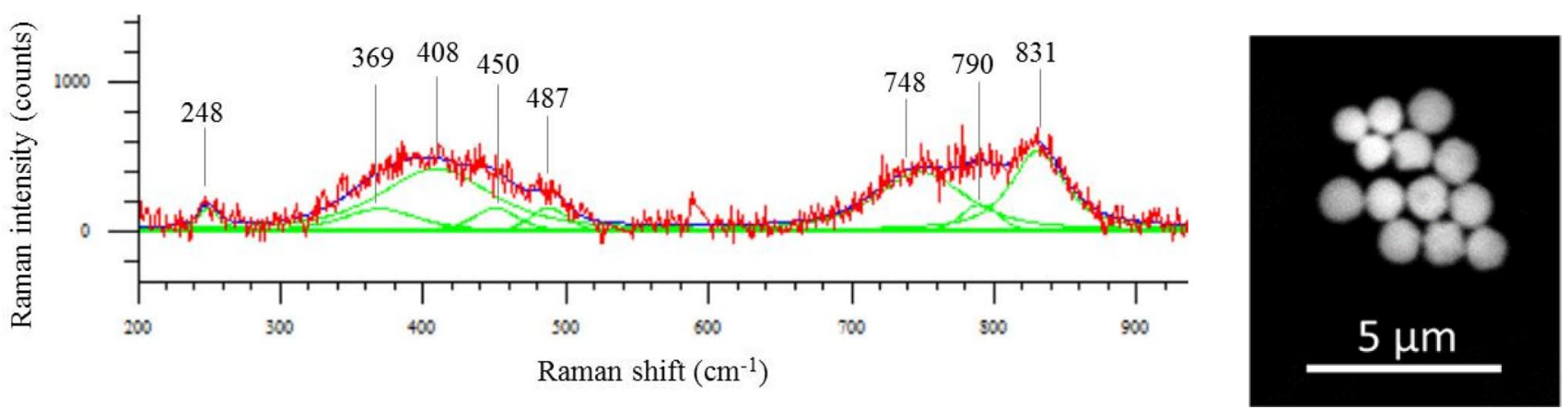

Fig. 2 Left: Background subtracted Raman spectrum of an individual U-oxide particle stored for two years under laboratory atmosphere. Modes are fitted and wavenumbers highlighted. Right: SEM micrograph of the measured agglomerate of particles

The EDS spectrum (inlet right) confirms the presence of $15 \% \mathrm{Nd}$ as expected in the mixed particles.

For structural investigations, the implementation of the combined SEM/Raman set-up is necessary as U-bearing particles are hardly identified by means of the optical microscope of the MRS and, moreover, may be confounded with the numerous environmental particles which accidentally deposit on the discs.

Figure 2 (right) shows the SEM micrograph of accidently agglomerated U-oxide particles and the in-SEM Raman spectrum (left) carried out on individual particles. Determined Raman bands have been matched to previously observed reference values. Measured peak centres mainly

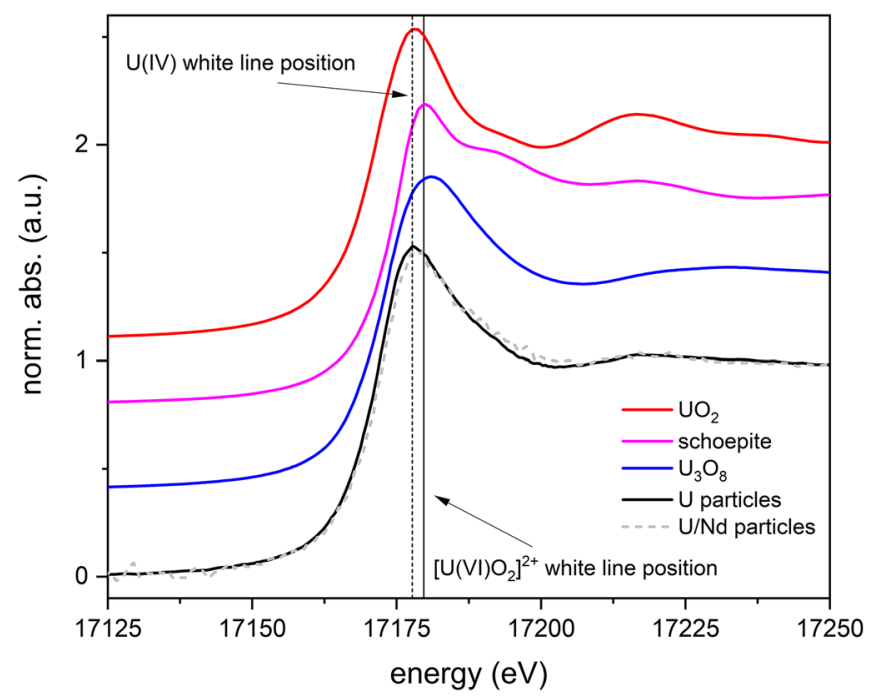

Fig. 3 Left: Normalised $\mathrm{U} \mathrm{L}_{3}$-XANES spectra of $\mathrm{U}$ (black solid line) and $\mathrm{U} / \mathrm{Nd}$ (grey dashed lines) microparticles deposited on glass discs in comparison to $U$ reference compounds (spectra vertically shifted for clarity). The vertical dashed line indicates the position of the white line maximum obtained for $\mathrm{UO}_{2}(17,177.72 \mathrm{eV})$ and the vertical solid line that obtained for schoepite $(17,179.73 \mathrm{eV})$. The sample was stored for four months under laboratory atmosphere before meas- match known stretching vibrations of $\mathrm{U}_{3} \mathrm{O}_{8}$ or are at least in their range (Table A1, Supplementary). The characteristic triplet feature between 300 and $500 \mathrm{~cm}^{-1}$ of $\mathrm{U}_{3} \mathrm{O}_{8}$ is clearly visible, along with a broad band at $\sim 750 \mathrm{~cm}^{-1}$ and a medium weak band at $\sim 800 \mathrm{~cm}^{-1}$. These measured wavenumbers are in good agreement with data reported in the literature for $\mathrm{U}_{3} \mathrm{O}_{8}[10,1 \mathrm{~S}-10 \mathrm{~S}]$. Besides, a weak band is also observed at $\sim 450 \mathrm{~cm}^{-1}$, which may correspond to presence of a minor $\mathrm{UO}_{2}$ phase [11S,12S] and a strong band at $\sim 830 \mathrm{~cm}^{-1}$, which is characteristic of hydrated highly oxidised U-oxide compounds like schoepite [13S-15S] due to the storage time of about two years. It should be mentioned that the intensity of the latter band varies significantly from

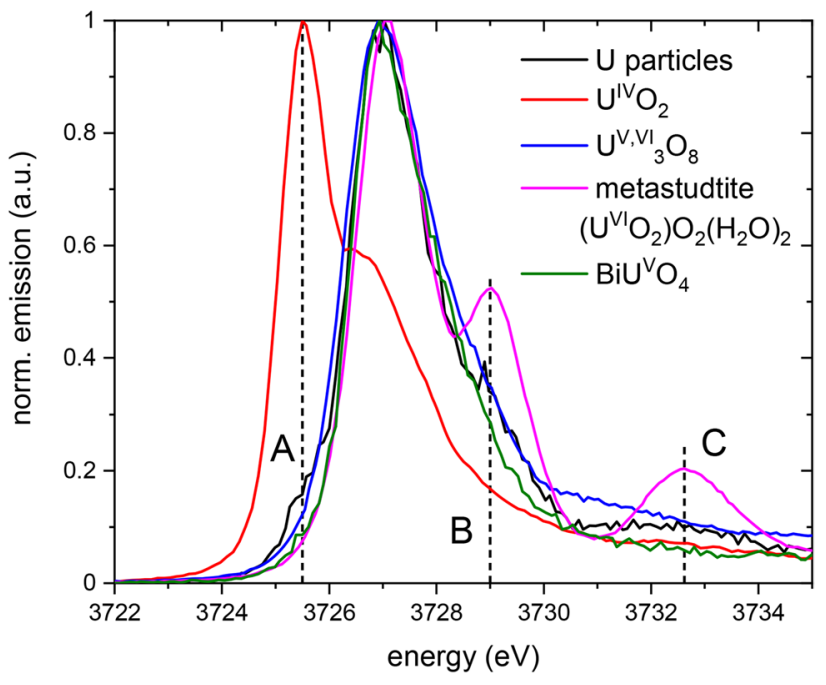

urement. Right: Normalised $\mathrm{U} \mathrm{M}_{4}$ HR-XANES spectra of U microparticles deposited on a glass disc (black solid line) in comparison to $\mathrm{U}$ reference compounds. The vertical dashed line $\mathrm{A}$ indicates the WL position obtained for $\mathrm{UO}_{2}(3725.5 \mathrm{eV})$, lines B and C mark spectral features characteristic for uranyl-type species as in schoepite or metastudtite. The sample was stored for ten months under laboratory atmosphere before measurement 
one spectrum to another. No band is visible at $\sim 630 \mathrm{~cm}^{-1}$, which is the dominant Raman band of $\mathrm{U}_{4} \mathrm{O}_{9}[11 \mathrm{~S}]$.

Figure 3, left depicts a comparison of the normalised $\mathrm{U}$ $\mathrm{L}_{3}$-XANES spectra obtained for $\mathrm{U}$ and $\mathrm{U} / \mathrm{Nd}$ microparticles and oxidic $\mathrm{U}$ reference compounds- $\mathrm{U}(\mathrm{IV}) \mathrm{O}_{2}, \mathrm{U}_{3} \mathrm{O}_{8}$ (data originally published in Böhler et al. [16]) and schoepite (hydrated $\mathrm{UO}_{3}$ with $\mathrm{U}(\mathrm{VI})$ present in the uranyl moiety $\left.\left[\mathrm{U}(\mathrm{VI}) \mathrm{O}_{2}\right]^{2+}\right)$. The latter spectra have been vertically shifted for clarity. The positions of the most prominent resonance ('white line', WL) corresponding to $2 \mathrm{p}_{3 / 2} \rightarrow 6 \mathrm{~d}$ transitions of the excited core electron coincide for the microparticle samples at $\sim 17,177.7 \mathrm{eV}$, in line with the value of $17,177.72 \mathrm{eV}$ obtained for $\mathrm{UO}_{2}$. The absence of the characteristic multiple scattering feature visible as a shoulder at the WL high-energy flank in case of uranyl (like schoepite) or uranate species (not shown) points to the absence of $U$ dioxo-moieties in the microparticles. However, those might exist as minority species not detectable by the limited energy resolution of the standard $\mathrm{L}_{3}$-edge technique $(<5 \%)$. At the given signal to noise ratio, significant differences between $\mathrm{U}$ and $\mathrm{U} / \mathrm{Nd}$ microparticles (grey dashed lines) are not discernible from these measurements. The average oxidation state of $\mathrm{U}$ in the microparticles seems to be lower compared to that in $\mathrm{U}_{3} \mathrm{O}_{8}$ (a non-stoichiometric $\mathrm{U}(\mathrm{V}) / \mathrm{U}(\mathrm{VI})$ oxide characterised by the absence of uranyl species, WL maximum at $17,180.9 \mathrm{eV}$ ) and schoepite (WL maximum at $17,179.73 \mathrm{eV})$. However, note the WL position anomaly in case of the latter compound due to the charge transfer effect of the axial, closely bond 'yl'-oxygen neighbours, which might explain the WL position shift to lower energy observed for schoepite compared to $\mathrm{U}_{3} \mathrm{O}_{8}$.

Detailed analysis of the $\mathrm{U} \mathrm{L}_{3}$-EXAFS data obtained for the $\mathrm{U}$ microparticles will be discussed in a forthcoming publication.

Complementarily, Fig. 3, right depicts the $\mathrm{U} \mathrm{M}_{4} \mathrm{HR}$ XANES spectra (normalised to their WL maxima) obtained for the pure $\mathrm{U}$ microparticles and the oxidic $\mathrm{U}$ references $\mathrm{U}(\mathrm{IV}) \mathrm{O}_{2}, \mathrm{U}(\mathrm{V}, \mathrm{VI})_{3} \mathrm{O}_{8}$, metastudtite (with $\mathrm{U}(\mathrm{VI})$ present in the uranyl moiety as in schoepite, data originally pub-

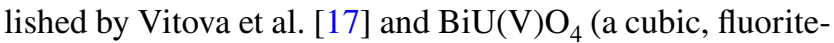
type $\mathrm{U}(\mathrm{V})$ phase, data originally published by Popa et al. [18]). The pronounced WL in the HR-XANES spectrum of $\mathrm{U}(\mathrm{IV}) \mathrm{O}_{2}$ at $3725.5 \mathrm{eV}$ is due to dipole-allowed electronic transitions from the uranium $3 \mathrm{~d}_{3 / 2}$ core level to the unoccupied 5f states (dashed line A in Fig. 3, right). Due to the superior energy resolution of the $\mathrm{M}_{4}$-edge HR-XANES technique, this spectral feature is highly sensitive to the $\mathrm{U}$ oxidation state or mixtures thereof. Note that the WL positions of the higher-valent $\mathrm{U}$ species are shifted by $\sim 1.5$ to $1.7 \mathrm{eV}$ to higher photon energies, with metastudtite exhibiting the highest value. Moreover, additional spectral features on the WL high-energy side (dashed lines B and C in Fig. 3, right) are characteristic for the presence of 'yl'-oxygen bonds as in schoepite or metastudtite (cf. [19] for details). Comparing the $\mathrm{U} \mathrm{M}_{4}$ HR-XANES obtained for the $\mathrm{U}$ microparticles to the reference compounds in Fig. 3, right, one can conclude that $\mathrm{U}$ in the particles is mostly present in pentavalent state with fluorite-type coordination. Those species coexist with small admixtures of $\mathrm{U}(\mathrm{IV}) \mathrm{O}_{2}$ and uranyl-type species (cf. shoulder in the rising edge at the U(IV) WL position and uranyl features at $3729.0 \mathrm{eV}$ and $3732.6 \mathrm{eV}$, respectively). The latter underpin the presence of schoepite that was observed in Raman measurements.

At a first glance the results from Raman and XANES measurements seem to be quite contradictory. However, the data sets recorded at different time intervals after the original particle synthesis together with the existing literature allow for a conclusive interpretation of the spectroscopic observations. The pristine particles are produced from dried U-nitrate droplets by decomposition in an aerosol heater at $500{ }^{\circ} \mathrm{C}$. Higgs et al. [20] published a $\mathrm{U}-\mathrm{O}$ phase diagram showing a stability field of coexisting $\mathrm{U}_{4} \mathrm{O}_{9}(\mathrm{U}(\mathrm{IV}) / \mathrm{U}(\mathrm{V}))$ and $\mathrm{U}_{3} \mathrm{O}_{8}(\mathrm{U}(\mathrm{V}) / \mathrm{U}(\mathrm{VI}))$ at temperatures above $507^{\circ} \mathrm{C}$ which is comparable to the settings of the particle production process. However, our initial $\mathrm{L}_{3}$-edge XANES measurements performed on "freshly" produced particles clearly indicate the predominance of $\mathrm{U}(\mathrm{IV})$ species in the particles. Note that the spectral shape (WL and post-edge resonance) observed for the particles clearly differs from that obtained for the fluorite-type $\mathrm{UO}_{2}$ reference, pointing to a different molecular structure of both $\mathrm{U}$ compounds. In contrast to that, the 6 month later obtained $\mathrm{M}_{4}$-edge XANES measurements indicate a gradual $\mathrm{U}$ oxidation with the predominance of $\mathrm{U}(\mathrm{V})$ species. In contrary, the Raman results point to the formation of a $\mathrm{U}_{3} \mathrm{O}_{8}$ phase with minor fraction of hydrated $\mathrm{UO}_{3}$ (schoepite). Raman spectroscopy is surface sensitive as the laser beam penetrates only a few tens of nanometres into the sample, particularly if the materials consist of heavy metal ions such as U. Since the particles' surface oxidises and weathers by adsorbing water molecules over time a $\mathrm{U}_{3} \mathrm{O}_{8}$ particle crust containing traces of schoepite is formed while the ageing process of the inner part of the particles is kinetically hindered. In XANES measurements the entire volume of the particle contributes to the data collection. Thus the mixed oxidation state of the U(IV) and U(V) of the inner part of the particle material dominates the XANES results.

\section{Conclusions}

Well-defined micrometre-sized U-oxide-based particles are accessible by the aerosol-method established in Juelich. In Raman measurements, a $\mathrm{U}_{3} \mathrm{O}_{8}$ structure was observed for pure U-oxide particles whereas the XANES measurements suggest mainly $\mathrm{U}(\mathrm{IV})$ (in $\mathrm{L}_{3}$-edge measurements) and $\mathrm{U}(\mathrm{V}$ ) (in $\mathrm{M}_{4}$-edge measurements) with traces of schoepite and 
$\mathrm{UO}_{2}$ detected by the latter method. This difference could be mainly explained by surface ageing/weathering effects of the particles being in contact with humidity of the surrounding environment. The observation of U(IV) in rather "freshly" prepared particles utilising the aerosol-based method was not published so far. From these results important conclusions can be drawn regarding the stability of particles in dependence on their storage conditions, i.e. in inert, humidity free atmosphere. A specific comprehensive shelf life study is in preparation.

The applicability of pure U-oxide particles as reference materials for analytical measurements has been recently demonstrated. The first batch of these microparticles has been successfully certified regarding the isotopic composition and the amount $\mathrm{U}$ per particle [21] and was utilised as reference materials in an international inter-laboratory exercise NUSIMEP-9 (NUclear Signatures Inter-laboratory Measurement Evaluation Programme) [22].

Acknowledgments Open Access funding enabled and organized by Projekt DEAL. The work was supported by the Federal Ministry of Economic Affairs and Energy, Germany in the framework of the German Support Programme to the IAEA (Task C45/A1961). We acknowledge the KIT light source for provision of instruments at the INEBeamline and ACT station and we would like to thank the Institute for Beam Physics and Technology (IBPT) for operation of the storage ring, the Karlsruhe Research Accelerator (KARA).

Data availability The datasets generated during and/or analysed during the current study are available from the corresponding author on reasonable request.

\section{Compliance with ethical standards}

Conflict of interest On behalf of all authors, the corresponding author states that there is no conflict of interest.

Research involving human participants/animals Within this work no experiments on human and animal subjects are reported.

Open Access This article is licensed under a Creative Commons Attribution 4.0 International License, which permits use, sharing, adaptation, distribution and reproduction in any medium or format, as long as you give appropriate credit to the original author(s) and the source, provide a link to the Creative Commons licence, and indicate if changes were made. The images or other third party material in this article are included in the article's Creative Commons licence, unless indicated otherwise in a credit line to the material. If material is not included in the article's Creative Commons licence and your intended use is not permitted by statutory regulation or exceeds the permitted use, you will need to obtain permission directly from the copyright holder. To view a copy of this licence, visit http://creativecommons.org/licenses/by/4.0/.

\section{References}

1. K.G.W. Inn, C.M. Johnson, W. Oldham, S. Jerome, L. Tandon, T. Schaaff, R. Jones, D. Mackney, P. MacKill, B. Palmer, D. Smith,
S. LaMont, J. Griggs, J. Radioanal. Nucl. Chem. 296(1), 5-22 (2012)

2. Y. Ranebo, P.M.L. Hedberg, M.J. Whitehouse, K. Ingeneri, S. Littmann, J. Anal. At. Spectrom. 24, 277-287 (2009)

3. S. Boulyga, S. Konegger-Kappel, S. Richter, L. Sangély, J. Anal. At. Spectrom. 30(7), 1469-1489 (2015)

4. N. Erdmann, M. Betti, O. Stetzer, G. Tamborini, J.V. Kratz, N. Trautmann, J. van Geel, Spectrochim Acta B 55, 1565-1575 (2000)

5. T.R. Pope, W. Kuhne, B.W. Arey, M.M. Zimmer, M. DeVore II., A.T. Baldwin, C. Padilla-Cintron, N.C. Anheier, M.G. Warner, M.S. Wellons, C.A. Barrett, ESARDA Bul. 59, 29-38 (2019)

6. J. Manaud, J. Maynadie, A. Mesbah, M. Hunault, P.M. Martin, M. Zunino, D. Meyer, N. Dacheux, N. Clavier, Inorg. Chem. 59(5), 3260-3273 (2020)

7. V. Trillaud, J. Maynadié, J. Manaud, J. Hidalgo, D. Meyer, R. Podor, N. Dacheux, N. Clavier, CrystEngComm 20(48), 7749_ 7760 (2018)

8. R. Middendorp, M. Klinkenberg, M. Dürr, J. Radioanal. Nucl. Chem. 318, 907-914 (2018)

9. S. Neumeier, R. Middendorp, A. Knott, M. Dürr, M. Klinkenberg, F. Pointurier, D.F. Sanchez, V.-A. Samson, D. Grolimund, I. Niemeyer, D. Bosbach, MRS Adv. 3(19), 1005-1012 (2018)

10. R. Middendorp, M. Dürr, A. Knott, F. Pointurier, D. Ferreira Sanchez, V. Samson, D. Grolimund, Anal. Chem. 89(8), 47214728 (2017)

11. R. Middendorp, M. Dürr, I. Niemeyer, D. Bosbach, ESARDA Bull. 54, 23-30 (2017)

12. J. Rothe, S. Butorin, K. Dardenne, M.A. Denecke, B. Kienzler, M. Löble, V. Metz, A. Seibert, M. Steppert, T. Vitova, C. Walther, H. Geckeis, Rev. Sci. Instrum. 83, 043105 (2012)

13. B. Ravel, M. Newville, J. Synchrotron Rad. 12, 537-541 (2005)

14. A. Zimina, K. Dardenne, M.A. Denecke, D.E. Doronkin, E. Huttel, H. Lichenberg, S. Mangold, T. Pruessmann, J. Rothe, T. Spangenberg, S. Steininger, T. Vitova, H. Geckeis, J.-D. Grunwaldt, Grunwaldt. Rev. Sci. Instrum. 88, 113113 (2017)

15. G. Kauric, O. Walter, A. Beck, B. Schacherl, O. Dieste Blanco, J.-F. Vigier, E. Zuleger, T. Vitova, K. Popa, Mater. Today Adv. 8, $100105(2020)$

16. R. Böhler, M.J. Welland, D. Prieur, P. Cakir, T. Vitova, T. Pruessmann, I. Pidchenko, C. Hennig, C. Guéneau, R.J.M. Konings, D. Manara, R. Böhler et al., J. Nucl. Mater. 448, 330-339 (2014)

17. T. Vitova, I. Pidchenko, D. Fellhauer, P.S. Bagus, Y. Joly, T. Pruessmann, S. Bahl, E. Gonzalez-Robles, J. Rothe, M. Altmaier, M.A. Denecke, H. Geckeis, Nat. Commun. 8, 16053 (2017)

18. K. Popa, D. Prieur, D. Manara, M. Naji, J.-F. Vigier, P.M. Martin, O. Dieste Blanco, A.C. Scheinost, T. Prüßmann, T. Vitova, P.E. Raison, J. Somers, R.J.M. Konings, Dalton Trans. 45, 7847-7855 (2016)

19. T. Vitova, I. Pidchenko, S. Biswas, G. Beridze, P.W. Dunne, D. Schild, Z. Wang, P.M. Kowalski, R.J. Baker, Inorg. Chem. 57(4), 1735-1743 (2018)

20. D. Higgs, B.J. Lewis, W.T. Thompson, Z. He, J. Nucl. Mater. 366, 99-128 (2007)

21. J. Truyens, M. Dürr, Z. Macsik, R. Middendorp, S. Neumeier, S. Richter, G. Stadelmann, C. Venchiarutti, Y. Aregbe, EUR29840, Publications Office of the European Union, Luxembourg, (2020) ISBN (978-92-76-09878-2), JRC117635.

22. C. Venchiarutti, S. Richter, R. Middendorp, Y. Aregbe, EUR 29822 EN, Publications Office of the European Union, Luxembourg (2019) ISBN 978-92-76-09182-0, JRC117415 